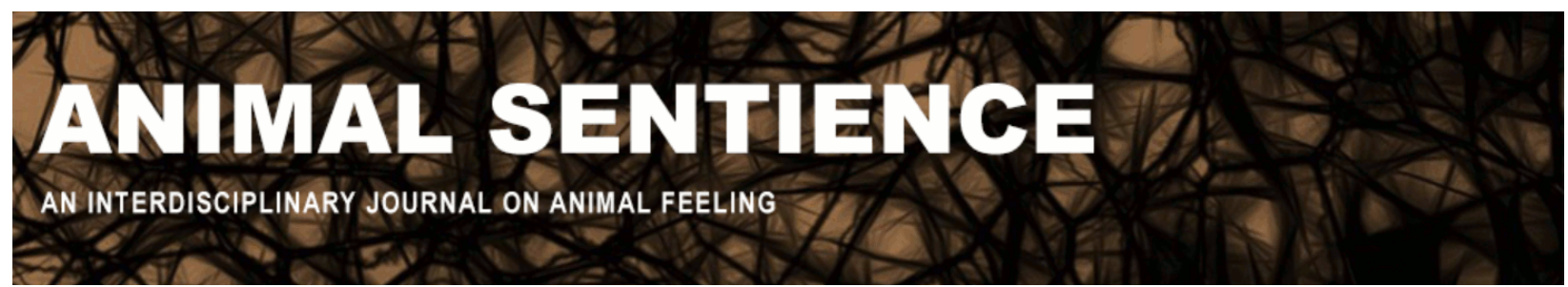

Shackelford, Todd K. (2018) Can they suffer?. Animal Sentience 23(4) DOI: $10.51291 / 2377-7478.1380$

Date of submission: 2019-01-24

Date of acceptance: 2019-01-31

(c) (i)




\title{
Can they suffer?
}

Commentary on Chapman \& Huffman on Human Difference

\author{
Todd K. Shackelford \\ Department of Psychology \\ Oakland University
}

\begin{abstract}
We should treat sentient nonhuman animals as worthy of moral consideration, not because we share an evolutionary history with them, but because they can suffer. As Chapman \& Huffman (2018) argue, humans are not uniquely disconnected from other species. We should minimize the suffering we inflict on sentient beings - whether human or nonhuman - not because they, too, are tool-makers or have sophisticated communication systems, but because they, too, can suffer, and suffering is bad.
\end{abstract}

Todd K. Shackelford is Co-Director of the Evolutionary Psychology Laboratory, Oakland University, and Editor of Evolutionary Psychology and Evolutionary Psychological Science. Much of his research addresses sexual conflict in humans. Website

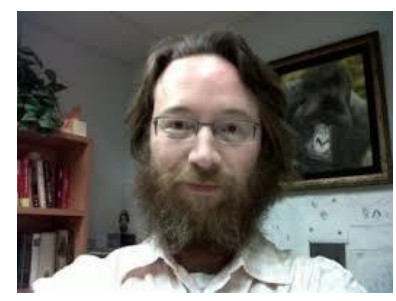

Evolution by natural selection is a fact as sure as gravity. As Chapman \& Huffman (2018) (C \& H) argue, this means that humans are not uniquely disconnected from other species. But, in contrast to the argument presented by $\mathrm{C} \& \mathrm{H}, \mathrm{I}$ think this is not relevant to why we should treat nonhuman animals as we treat those humans we care about (and as we should treat all humans). Whether we share a particular trait (e.g., tool-making) is not relevant to whether we should treat sentient nonhuman animals as worthy of moral consideration. As Bentham (1789) spelled out over two centuries ago:

The day may come when the rest of the animal creation may acquire those rights which never could have been witholden from them but by the hand of tyranny. The French have already discovered that the blackness of the skin is no reason a human being should be abandoned without redress to the caprice of a tormentor. It may one day come to be recognised that the number of the legs, the villosity of the skin, or the termination of the os sacrum are reasons equally insufficient for abandoning a sensitive being to the same fate. What else is it that should trace the insuperable line? Is it the faculty of reason or perhaps the faculty of discourse? But a full-grown horse or dog, is beyond comparison a more rational, as well as a more conversable animal, than an infant of a day or a week or even a month, old. But suppose the case were otherwise, what would it avail? The question is not, Can they reason? nor, Can they talk? but, Can they suffer.

To a first approximation, any living being with a brain can suffer and, therefore, warrants moral consideration. Whether these beings were poofed into existence by a god or gods is not relevant - it matters not whether we share an evolutionary history with them (of course, I recognize that 
we do). We should behave so as to minimize the suffering we inflict on sentient beings - whether human or nonhuman - not because they, too, are tool-makers; not because they, too, have sophisticated communication systems. We should minimize suffering because suffering is bad. We should not farm sentient animals like cows, chickens, and pigs, for example, for the same reason that we should not farm humans: Because farming them inflicts unnecessary suffering on them. I certainly agree with the conclusion of the arguments presented by C \& H. But I think it is not relevant whether and to what degree we share a particular trait - with one exception. The only trait that matters - the only morally considerable trait - is sentience. We should work hard to minimize the suffering we inflict on sentient life. It is irrelevant whether that sentient life is human or nonhuman.

\section{References}

Bentham, J. (1789). An Introduction to the Principles of Morals and Legislation. London: T. Payne and Son.

Chapman, C. A. and Huffman, M. A. (2018). Why do we want to think humans are different? Animal Sentience 23(1). 